\title{
[postprint version]
}

The role of satisfaction with social support in perceived burden and stress of parents of six-month-old infants with a congenital anomaly: Actor and partner effects

\section{Ana Fonseca, Bárbara Nazaré, \& Maria Cristina Canavarro}

\section{Abstract}

This exploratory study examined the role of satisfaction with support from family and friends on the burden and stress of parents of infants with a congenital anomaly (CA). The effects of social support were examined within the couple (actor and partner effects).

Thirty-six couples whose six-month-old infant has a CA participated in this study. The parents completed questionnaires regarding satisfaction with support, burden (Impact on Family Scale-Revised) and parenting stress (Parenting Stress Index).

The results showed that fathers directly benefited from the support they received from friends in reducing their burden, while mothers only indirectly benefited from it through the father's adjustment. The pattern was different for stress: mothers directly benefited from the support they received from their family in reducing their stress levels, while fathers benefited both directly from the support they received from friends and indirectly from the support that their partners received from family. 
These results highlight that: 1) the different support needs of mothers and fathers (due to their different roles during transition to parenthood) and 2) the diffusion of benefits of social support within the couple should be taken into account when developing strategies to promote support to families of six-month-old infants with a CA. Key-words

Actor-partner effects, burden, parenting stress, parents of infants with a congenital anomaly, social support. 


\section{Introduction}

The first months of parenthood may be particularly demanding for parents who raise an infant with a congenital anomaly (CA). CAs are structural or functional anomalies present at birth that arise during intra-uterine development (e.g., congenital heart disease, cleft lip and palate, Crowley, 2010). The estimated prevalence of live births with CA in European countries was 179.81 per 10.000 births, in 2010 (EUROCAT, 2012). In addition to the usual caretaking tasks, parents must adapt to the challenges associated with the CA, as surgeries, hospitalizations, increased medical monitoring, and uncertainty about the future quality of life (Mazer et al., 2008). The infant's CA may have familial/social, and professional/financial costs for parents, which may be reflected in the parents' perceived burden (Hunfeld et al., 1999) and parenting stress (Uzark and Jones, 2003). Given these increased demands, it is important to understand which resources - namely social support - should be fostered to help parents of infants with a CA to adapt to the condition.

\section{Benefits of social support for parents during transition to parenthood}

Social support is a type of interpersonal transaction that includes appraisal, emotional concern, information, or instrumental aid (House, 1981). Therefore social 
support is a resource to meet the individual's specific needs in a given period of life (Tak and McCubbin, 2002) and to deal with stressful situations. Social support has been considered an important resource during transition to parenthood among parents of healthy infants (Bost et al., 2002). During this period, the parents' main needs of support are related with the responsibilities and everyday tasks of parenthood (Bost et al., 2002). Therefore, parents become closer to their nuclear family and more distant from their friends, as a way of surrounding themselves with sources of support that appropriately meet their parental needs (social nesting; Gameiro et al., 2010).

Although the benefits of social support also occur in parents of children who possess a CA (Murray et al., 2007), some specificities make it important to further examine the nature of these effects: 1) this is a period of intense learning related to the diagnosis specificities (Griffin, 2002), so these parents' support needs may be different (e.g., needs for information, Sargent, 2009); 2) parents may have some communication difficulties within their social network concerning the diagnosis, such as sharing the news of the diagnosis (Howard, 2006), or dealing with the reactions from their social network about the infant's diagnosis (Messias et al., 1995).

Research on the role of social support in the adjustment of parents of children with a CA has focused in parents of older children and shows a positive impact of overall satisfaction with received support on the perceived burden of parents of children (mean age: eight years) with developmental disabilities (Jones and Passey, 2004) and of 
parents of children (mean age: 12 years) with intellectual disabilities (Mak and Ho, 2007). Moreover, increased satisfaction with support was associated with reduced levels of parenting stress in parents of infants with cerebral palsy (Britner et al., 2003) and in parents of children (ages between four and 18 years) with spina bifida (Macias et al., 2007). Guralnick et al. (2008) found that specific support related to help with childcare or advice about the child's problems, but not general emotional or instrumental support, significantly contributed to the reduction of maternal stress levels when parenting a child with a disability. Consistently, parents of infants with a CA acknowledged their family (including the partner, their own and their partner's nuclear family) as their greatest source of support (Findler, 2000; Hornby and Ashworth, 1994; Jones and Passey, 2004; Tunali and Power, 2002), with the support received from friends being perceived as less helpful (Hall and Graff, 2011). However, it is important to examine the effects of the satisfaction with support from different sources in the adjustment of parents of younger children with a CA.

During the transition to parenthood, mothers assume the role of main caregivers of the infant while fathers are the family's providers (Katz-Wise et al., 2010), so their support needs may be different. Also, studies have shown that social support seems to be more relevant to mothers' than for fathers' adjustment (Levy-Shiff, 1999). Social support was found to be beneficial for both mothers and fathers of infants with a CA (Macias et al., 2007), while others found benefits only for mothers (Krauss, 1993), 
suggesting a distinct effect of social support for both genders. This should be further explored.

The Actor-Partner Interdependence Model: The benefits of social support within the couple

The Actor-Partner Interdependence Model (APIM; Cook and Kenny, 2005) is a model of interdependence in dyadic relationships, that is, when one person's emotion, cognition, or behavior affects the emotion, cognition, or behavior of a partner. Interdependence within the family system has been documented in other contexts, suggesting that the characteristics of one member of the couple influence the characteristics and outcomes of the other member (Barr, 2012; Dorros et al., 2010). As parenting is usually experienced jointly by the couple, this influence may become even more evident (Biehle and Mickelson, 2011). To our knowledge, the partner effects of support in parental adjustment, that is, the effects of one partner's perceived support on the other partner's adjustment, have not been investigated in the context of raising an infant with a CA. Furthermore, the APIM also suggests that the adjustment of both partners seems to be mutually influenced within the couple (Cook and Kenny, 2005). In fact, Gray (2003) found that fathers sometimes regarded the negative impact of dealing with their child's disability as an indirect impact that originated from their partner's distress and suffering. Therefore, it is reasonable to hypothesize that the effect of one 
parent's perceived social support influence his or her partner's adjustment, via an indirect mechanism through that parent's adjustment (i.e., the individual's perceived satisfaction with support influence his/her own adjustment which, in turns, influence his/her partner's adjustment).

Research aims and hypotheses

In accordance to the APIM (Cook and Kenny, 2005), we aimed to investigate the individual (actor) and partner effects of satisfaction with social support received from family and friends in parental adjustment (burden and parenting stress). We also aimed to explore whether the partner effects (the effects of maternal/paternal satisfaction with support on her or his partner's adjustment) occur indirectly, through maternal/paternal adjustment (see Figure 1).

\section{[Insert_Figure_1_about_here]}

We established the following hypotheses: 1) increased satisfaction with support from family and friends will predict better individual adjustment; 2) increased satisfaction with support will be positively associated with the partner's adjustment; and 3) the effect of mother's/father's perception of support on her or his partner's adjustment will be indirect through their own (mother's/father's) adjustment.

\section{Methods}




\section{Participants and Procedure}

This study is part of a longitudinal study entitled "Reproductive decisions and transition to parenthood after a pre- or postnatal diagnosis of a CA" which was approved by the Ethics Committees of the Hospitais da Universidade de Coimbra (HUC) and the Centro Hospitalar de Coimbra (CHC), Portugal. Inclusion criteria for the present study were: 1) having an infant who was pre- or postnatally diagnosed with a CA, without the occurrence of perinatal death; 2) being at least 18 years of age; and 3) having a level of literacy (educational level $\geq$ sixth grade) that allowed for comprehension of the assessment protocol.

The data collection took place between September 2009 and February 2012, in the Obstetrics and Neonatology Departments of HUC and in the Pediatric Cardiology Service of the Pediatric Hospital (CHC). Approximately one month after the disclosure of a diagnosis of a CA, all parents were informed about this study by their medical team at the end of a medical appointment and contacted by the researchers. Those who decided to participate signed an informed consent form and answered to the assessment protocol (Time 1). 82 couples were contacted, of whom 22 refused to participate/did not return the questionnaires (participation rate: 73.17\%). Parents were again contacted six months after the infant's birth (Time 2). The questionnaires were mailed to the participants along with a pre-stamped envelope in which to return them after completion; 17 couples did not return the questionnaires (attrition rate: $28.33 \%$ ), and 
seven questionnaires were excluded because they had been completed only by the mother. No significant differences in socio-demographical or clinical characteristics were found in parents who returned or did not return the questionnaires at Time 2 (data not shown). For the purpose of this study, only the couples who participated at Time 2 were considered.

The final sample comprised 36 couples. The sample characteristics are presented in Table 1. Mothers were younger and studied for longer than fathers. The majority of parents have learned about their infant's CA during the prenatal period.

[Insert_Table_1_about_here]

\section{Measures}

Socio-demographic and clinical data. Socio-demographic (e.g., gender, age, educational level, and professional status) and clinical information (e.g., parity; the infant's data: gender, gestational age at birth, type of CA, timing of diagnosis, and need for surgery) were obtained using a questionnaire.

Satisfaction with support received. The satisfaction with support received from family and friends was assessed by the question: "To what extent do you feel satisfied with the support received from the following persons, since your baby's birth?". For each source of support (partner, nuclear family, partner's nuclear family, and friends), the parents classified their amount of satisfaction, using visual analogue scales (from 0 $=$ Not satisfied to $100=$ Extremely satisfied ). Individual scores of satisfaction with their 
partner, their own family and their partner's family were averaged to compute an index of satisfaction with support received from their nuclear family.

Perceived burden. Burden was assessed using the Portuguese version of the Impact on Family Scale - Revised (IOF-R; Albuquerque et al., 2011). This unidimensional scale consists of 15 items (e.g., "Fatigue is a problem for me because of my child's illness"), answered in a four-point scale (from $1=$ Strongly disagree to $4=$ Strongly agree). Higher scores indicate a greater perceived burden associated with caring for an infant with a CA. The Cronbach's alpha values in our sample were .93 for mothers and .94 for fathers.

Parenting stress. The Portuguese version of the Parenting Stress Index - Short Form (PSI-SF; Santos, 2011) was used to evaluate stress within the parent-child system. The scale comprises 36 items (e.g., "I often have the feeling that I cannot handle things very well") answered on a five-point scale (from $1=$ Completely disagree to $5=$ Completely agree), and is organized along three dimensions: Parental Distress, ParentChild Dysfunctional Interaction, and Difficult Child. It is also possible to compute a total score of Parenting Stress, which was used in the present study. Higher scores indicate greater stress. The Cronbach's alpha values in our sample were .93 for fathers and .95 for mothers. 


\section{Data Analyses}

Analyses were conducted using IBM SPSS, version 19.0. Data analyses were performed on the couple as a unit. The database was restructured to consider each couple as the subject of the analysis and each partner's score as a different variable. Descriptive statistics and comparison tests (paired $t$-tests and chi-squared tests) were used for socio-demographic characterization of the sample. Bivariate Pearson correlations were computed among the study variables.

Multiple regression analyses were conducted to investigate the effects of social support (Satisfaction with support from family, Satisfaction with support from friends) on parental adjustment (dependent variables: Burden, Parenting Stress). In accordance with the APIM (Cook and Kenny, 2005), in one set of analyses the maternal outcome variables were regressed on the maternal (actor) and paternal (partner) predictor variables, and in the other set of analyses, the paternal outcome variables were regressed on the paternal (actor) and maternal (partner) predictor variables. The sociodemographic and clinical variables were introduced in the first step of the models for control purposes if they were significantly associated with parental adjustment.

When a partner effect on the actor's adjustment was found, we examined whether this was an indirect effect through the partner's adjustment. Indirect effects were examined using a procedure that relies on nonparametric bootstrapping, which is indicated for small samples and does not require the assumption of normality of the 
sampling distribution. The SPSS version of Preacher and Hayes' macro "Indirect" was used (Preacher and Hayes, 2004, 2008). The presence of an indirect effect was assessed with bootstrapping (with $N=5000$ resamples). Point-estimates and $95 \%$ confidence intervals (CI; Bias corrected and accelerated CI) were estimated for the indirect effects. An indirect effect was considered significant if zero was not included in the $95 \% \mathrm{CI}$.

Post-hoc power calculations made for all statistical analyses performed with a significance level of .10 and power $\geq .80$ indicated that medium to large effects $\left(\mathrm{f}^{2} \geq\right.$ .30) could be detected (Faul et al., 2007). As a result, significance was defined as p < .05 but marginally significant results $(\mathrm{p} \leq .10)$ were also reported.

\section{Results}

Table 2 presents descriptive statistics and the bivariate associations between sociodemographic and clinical variables, social support and parental adjustment.

$$
\text { [Insert_Table_2_about_here] }
$$

As shown in Table 2, maternal satisfaction with support from family and friends was significantly and negatively correlated with maternal and paternal parenting stress, but not with burden. Paternal satisfaction with support from family was only marginally significantly correlated with paternal levels of stress, while paternal satisfaction with support from friends was significantly correlated with paternal burden and with maternal and paternal stress. Moreover, maternal and paternal satisfaction with support 
from family were not significantly correlated, while maternal and paternal satisfaction with support from friends showed moderate correlations. Finally, both maternal and paternal adjustment indicators were significantly and positively correlated.

Actor and partner effects of social support on parental adjustment

Table 3 presents the regression models assessing the actor and partner effects of satisfaction with social support in the maternal and paternal adjustment (burden and parenting stress).

\section{[Insert_Table_3_about_here]}

Burden. The model predicting maternal burden was marginally significant. As shown in Table 3, the maternal perceived burden was lower when mothers had no other children and when their partners were more satisfied with the support they received from friends (partner effect). Similarly, the model predicting paternal burden was significant. Fathers perceived lower burden when they had no other children and when they were more satisfied with the support they received from friends (actor effect).

Parenting stress. The models predicting maternal and paternal parenting stress were both significant. As shown in Table 3, an actor effect of satisfaction with support from family was found for maternal stress: higher maternal satisfaction with support received from their family predicted lower levels of maternal stress. When considering 
paternal levels of stress, an actor and a partner effect were found: fathers presented lower levels of parenting stress when they were more satisfied with the support received from their friends (actor effect) and when their partners were more satisfied with the support received from the family (partner effect).

Partner effects: Indirect effects through the partner's adjustment

Table 4 presents the indirect effects of the partner's satisfaction with support on the actor's adjustment through the partner's adjustment.

$$
\text { [Insert_Table_4_about_here] }
$$

As shown in Table 4, an indirect effect in the relationship between the paternal satisfaction with the support received from their friends and maternal burden was found, through paternal burden. When fathers were more satisfied with the support they received from their friends, they perceive lower burden which, in turn, was reflected in lower maternal burden. Moreover, a significant indirect effect was found in the relationship between maternal satisfaction with the support received from the family and paternal parenting stress. When mothers were more satisfied with the support received from their family, they presented lower levels of maternal stress which, in turn, contributed to decreased paternal levels of stress. 


\section{Discussion}

The main finding of this exploratory study was that both parents of six-month-old infants with a CA benefited from social support. However, the benefits of social support were different when considering mothers or fathers, perceived burden or parenting stress, and family or friends as sources of support. Moreover, social support had a positive impact not only on the individual's adjustment, but also on the partner's adjustment, which suggests a diffusion of its benefits.

As shown by our results, mothers benefited directly from support offered by their family, which reduced their parenting stress levels, partially confirming our first hypothesis. The mothers' partners and nuclear family (their own and their partner's) are usually the main providers of instrumental and emotional assistance with usual childcare tasks (Bost et al., 2002), reducing maternal stress associated with the parenting role. Consistent with the study by Guralnick et al. (2008), the most useful dimension of support for mothers of infants with a CA seems to be the support related with help with childcare or advice about the child's problems. Conversely, and contrary to our expectations, maternal satisfaction with support received was not associated with a decrease in maternal burden. Mothers only benefited indirectly from the support received from their partner's friends, through father's perceived burden, supporting the APIM model. It is possible that help with childcare may be useful in terms of emotional consequences (maternal stress), but not in terms of the objective impact of the CA, such 
as familial routines, financial issues, interaction with medical services. Therefore, the maternal perceived burden of caring for an infant with a CA may be more effectively reduced with the support from other sources, as health professionals or social services. This hypothesis should be further explored.

The support received from friends was not beneficial for maternal adjustment. Similarly to mothers of healthy infants (Gameiro et al., 2010), mothers of infants with a CA may distance themselves from their social network (e.g., friends) during the first months of parenthood. This withdrawal may be due to the time spent in providing care to the infant (Lawoko and Soares, 2003), or with some difficulties in communicating about diagnosis-related issues (Messias et al., 1995). The lack of contact with friends may lead to lower maternal satisfaction with the support received from them, but also to its lower impact on maternal adjustment.

A different pattern of results was found for fathers. In fact, fathers benefited directly from the support they received from friends in reducing their perceived burden and parenting stress. Three reasons may explain our results. First, despite participating in some caregiving tasks, fathers usually assume the role of economic providers for the family (Katz-Wise et al., 2010). Thus, as opposed to the mothers' needs, fathers' support needs may be more related with assistance with financial or legal issues, or increased flexibility with work issues, so their friends can be a useful source of help. Second, fathers may have more opportunities than mothers for interaction within their 
social network (friends) given their earlier return to work and to daily routines (Feldman et al., 2004). As suggested by Olsson and Hwang (2006), the greater paternal involvement in the professional responsibilities seems to be associated with better wellbeing for fathers, compared to their partners. It is possible that, due to this involvement, fathers receive and benefit more from their friends' support. Third, research shows that fathers try to assume the protective role of their partners (Locock and Alexander, 2006), trying not to show their own suffering, as we explain below. Therefore, fathers may rely more on friends than on their family for emotional support to deal with the emotional constraints associated with the parenting experience.

In fact, paternal satisfaction with support received from their family was not reflected in better paternal adjustment. Fathers may be concerned with their partners' suffering after the infant's diagnosis of a CA, seeking to direct their efforts to support and to protect them (Locock and Alexander, 2006). Therefore, fathers may neglect their own suffering and may avoid to adequately communicate their support needs to their partner or family, or even engage in help-seeking behaviors. Even when fathers receive support from their partner and family, they may be worried about their inability to fulfill their role as protectors. These factors may help to explain why support from family did not prove to be beneficial for paternal adjustment. However, fathers showed benefits in parenting stress when mothers were more satisfied with the support they received from the family, as suggested by the APIM model. This benefit was indirect through the 
mother's adjustment. As primary caregivers, mothers may experience more emotional constraints associated with the parenting role (i.e., parenting stress) than fathers. As maternal suffering associated with the impact of the child's diagnosis is sometimes reflected in fathers' adjustment (Gray, 2003), the factors which contribute to improve the maternal adjustment - in this case, social support - were also reflected in a better paternal adjustment. In fact, when mothers were more satisfied with the support received from their family, they may perceive fewer restrictions associated with the demands of parenting role, which reflects in reduced levels of maternal stress. Moreover, these reduced levels of maternal stress were likely reflected in better interactions within the couple (e.g., less conflict, improved communication), which consequently improved paternal adjustment. In sum, our results confirmed the diffusion of benefits of social support within the couple, supporting the interdependence in the dyadic relationships (Cook and Kenny, 2005).

Although the present study represents an important contribution to the field, it has several limitations. The first limitation is the study's reduced power to detect small effects due to the sample size. Second, the assessment of social support (overall satisfaction with support from different sources, assessed with single-items) did not allow to differentiate between different types of support (e.g., emotional, instrumental) provided by each source, which can be examined in future studies. The last limitation is the non-categorical approach to CA (that is, the inclusion of different types of CAs). 
Although our goal was to examine the common experience of these parents, future studies may investigate whether these patterns are similar for parents of infants with different types of CA.

The findings of the present study lead to some clinical implications. First, social support is a beneficial resource for adjustment among parents of infants with a CA during the first months of the infant's life, and this support should be a target of evaluation and should be promoted. However, it should be noted that mothers' and fathers' support needs are different, and that the effects of support are different for different adjustment indicators. Second, it should be noted that the demands of childcare prevent mothers from activating some sources of their social network (e.g., friends). In addition to the assessment of maternal satisfaction with the support received, it would be important to consider other issues, such as opportunities for interaction and for requesting help from friends who usually provide support. Third, given the diffusion of benefits of social support within the couple, both partners should be included in the assessment and intervention processes, and the mutual influences within the couple as well as the different mechanisms by which they may occur should be taken into account.

Finally, parents who report lower satisfaction with the support received from their network may be at a higher risk of poor adjustment and should be targeted for specialized counseling, to help them develop strategies for 1) identifying their support 
needs and sources in their social network who may provide that support; 2) communicating their support needs with their social network and activating helpseeking behaviors; and 3) communicating with different sources of support about satisfactory and unsatisfactory aspects of the support received to improve satisfaction with subsequent support.

\section{References}

Albuquerque S, Fonseca A, Pereira M, et al. (2011) Estudos psicométricos da versão Portuguesa da Escala de Impacto Familiar (EIF) [Psycomethric studies of the Portuguese version of the Impact on Family Scale] . Laboratório de Psicologia 9(2): 175-189.

Barr P (2012) A dyadic analysis of negative emotion personality predisposition effects with psychological distress in neonatal intensive care unit parents. Psychological Trauma: Theory, Research, Practice and Policy 4(4): 347-355

Biehle S and Mickelson K (2011) Personal and co-parent predictors of parenting efficacy across the transition to parenthood. Journal of Social and Clinical Psychology 30(9): 985-1010.

Bost K, Cox M, Burchinal M, et al. (2002) Structural and supportive changes in couples' family and friendship networks across the transition to parenthood. Journal of Marriage and Family 64(2): 517-531. 
Britner P, Morog M, Pianta R, et al. (2003) Stress and coping: A comparison of selfreport measures of functioning in families of young children with cerebral palsy or no medical diagnosis. Journal of Child and Family Studies 12(3): 335-348.

Cook W and Kenny D (2005) The actor-partner interdependence model: A model of bidirectional effects in developmental studies. International Journal of Behavioral Development 29(2): 101-109.

Crowley L (2010) An introduction to human disease: Pathology and pathophysiology correlations (8th ed.). Sudbury: Jones and Bartlett Publishers, LLC.

Dorros S, Card N, Segrin C, et al. (2010) Interdependence in women with breast cancer and their partners: An interindividual model of distress. Journal of Consulting and Clinical Psychology 78(1): 121-125.

European Surveillance of Congenital Anomalies [EUROCAT] (2012). Prevalence Tables. Available at: http://www.eurocatnetwork.eu/accessprevalencedata/prevalencetables (accessed 26 May 2012).

Faul F, Erdfelder E, Lang AG, et al. (2007) G*Power3: A flexible statistical power analysis program for the social, behavioral, and biomedical sciences. Behavior Research Methods 39: 175-191.

Feldman R, Sussman AL and Zigler E (2004) Parental leave and work adaptation at the transition to parenthood: Individual, marital and social correlates. Journal of Applied Developmental Psychology 25(4): 459-479. 
Findler LS (2000) The role of grandparents in the social support system of mothers of children with a physical disability. Families in Society 81(4): 370-381.

Gameiro S, Boivin J, Canavarro MC, et al. (2010) Social nesting: Changes in social network and support across the transition to parenthood in couples that conceived spontaneously or through assisted reproductive technologies. Journal of Family Psychology 24(2): 175-187.

Gray DE (2003) Gender and coping: The parents of children with high functioning autism. Social Science \& Medicine 56(3): 631-642.

Griffin T (2002) Supporting families of infants with congenital heart disease. Newborn and Infant Nursing Reviews 2(2): 83-89.

Guralnick MJ, Hammond MA, Neville B, et al. (2008) The relationship between sources and functions of social support and dimensions of child- and parent-related stress. Journal of Intellectual Disability Research 52: 1138-1154.

Hall $\mathrm{H}$ and Graff $\mathbf{J}$ (2011) The relationships among adaptative behaviors of children with autism, family support, parenting stress, and coping. Issues in Comprehensive Pediatric Nursing 34: 4-25.

Hornby G and Ashworth T (1994) Grandparents' support for families who have children with disabilities. Journal of Child and Family Studies 3(4): 403-412.

House JS (1981) Work stress and social support. Reading, MA: Addison-Wesley. 
Howard E (2006) Family-centered care in the context of fetal abnormality. Journal of Perinatal \& Neonatal Nursing 20(3): 237-242.

Hunfeld J, Tempels A, Passchier J, et al. (1999) Parental burden and grief one year after the birth of a child with a congenital anomaly. Journal of Pediatric Psychology 24(6): 515-520.

Jones J and Passey J (2004) Family adaptation, coping and resources: Parents of children with developmental disabilities and behaviour problems. Journal on Developmental disabilities 11(1): 31-46.

Katz-Wise S, Priess H and Hyde J (2010) Gender-role attitudes and behavior across the transition to parenthood. Developmental Psychology 46(1): 18-28.

Krauss MW (1993) Child-related and parenting stress: Similarities and differences between mothers and fathers of children with disabilities. American Journal on Mental Retardation 97: 393-204.

Lawoko S and Soares J (2003) Social support among parents of children with congenital heart disease, parents of children with other diseases and parents of healthy children. Scandinavian Journal of Occupational Therapy 10: 177-187.

Levy-Shiff R (1999) Fathers' cognitive appraisals, coping strategies, and support resources as correlates of adjusment to parenthood. Journal of Family Psychology 13(4): 554-567. 
Locock L and Alexander J (2006) Just a bystander? Men's place in the process of fetal screening and diagnosis. Social Science \& Medicine 62: 1349-1359.

Macias M, Saylor C, Haire K, et al. (2007) Predictors of paternal versus maternal stress in families of children with neural tube defects. Children's Healthcare 36(2): 99-115.

Mak W and Ho G (2007) Caregiving perceptions of chinese mothers of children with intellectual disability in Hong Kong. Journal of Applied Research in Intellectual Disabilities 20: 145-156.

Mazer P, Gischler SJ, Koot HM, et al. (2008) Impact of Child with Congenital Anomalies on Parents (ICCAP) questionnaire: A psychometric analysis. Health and Quality of Life Outcomes 6(102): 102-110.

Messias D, Gilliss C, Sparacino P, et al. (1995). Stories of transition: Parents recall the diagnosis of congenital heart defect. Family Systems Medicine 13(3/4): 367-377.

Murray C, Kelley-Soderholm E and Murray T (2007) Strengths, challenges, and relational processes in families of children with congenital upper limb differences. Families, Systems \& Health 25(3): 276-292.

Olsson MB and Hwang CP (2006) Well-being, involvement in paid work and division of child-care in parents of children with intellectual disabilities in Sweden. Journal of Intellectual Disability Research 50(12): 963-969. 
Preacher K and Hayes A (2004) SPSS and SAS procedures for estimating indirect effects in simple mediation models. Behavior Research Methods, Instruments \& Computers 36(4): 717-731.

Preacher K and Hayes A (2008) Asymptotic and resampling strategies for assessing and comparing indirect effects in multiple mediator models. Behavior Research Methods 40(3): 879-891.

Santos S (2011) Versão Portuguesa do Parenting Stress Index (PSI) - Forma Reduzida: Estudo com uma amostra de mães de crianças com idade inferior a 5 anos [Portuguese version of the Parenting Stress Index (PSI) - Short Form: Study with a sample of mothers of children with five years or younger]. Poster presented at the VIII Congresso Iberoamericano de Avaliação Psicológica/XV Conferência Internacional de Avaliação Psicológica: Formas e Contextos, Lisboa.

Sargent A (2009) Predictors of needs in mothers with infants in the neonatal intensive care unit. Journal of Reproductive and Infant Psychology 27(2): 195-205.

Tak YR and McCubbin M (2002) Family stress, perceived social support and coping following the diagnosis of a child's congenital heart disease. Journal of Advanced Nursing 39(2): 190-198.

Tunali B and Power TG (2002) Coping by redefinition: Cognitive appraisals in mothers of children with autism and children without autism. Journal of Autism and Developmental Disorders 32(1): 25-34. 
Uzark K and Jones K (2003) Parenting stress and children with heart disease. Journal of Pediatric Health Care 17: 163-168. 
Table 1 - Sample socio-demographic and clinical characteristics

Socio-demographic characteristics

\begin{tabular}{lccc}
\hline & Mothers & Fathers & \\
\hline & $M(S D)$ & $M(S D)$ & $t$ \\
\hline Age & $31.72(4.31)$ & $33.25(5.05)$ & $-1.77^{\dagger}$ \\
Educational level (years) & $14.60(3.30)$ & $12.11(2.73)$ & $5.31^{* *}$ \\
\hline Professional status & $n(\%)$ & $n(\%)$ & $\chi^{2}$ \\
Employed & $32(88.9)$ & $33(91.7)$ & 0.16 \\
Unemployed & $3(11.1)$ & $3(8.3)$ & \\
\hline Obstetric history and infant's data & & & \\
\hline
\end{tabular}

$n(\%) / M(S D)$

Parity

Primiparity

$18(50.0)$

Multiparity

$18(50.0)$

History of pregnancy loss

$\begin{array}{ll}\text { Yes } & 6(16.7) \\ \text { No } & 30(83.3)\end{array}$

Infant's age at birth

(gestational weeks)

$38.58(1.99)$

Sex

Male

$21(58.3)$

Female

$15(41.7)$

Infant's age at time 2

$6.64(0.90)$

CA characteristics 
Timing of diagnosis

$\begin{array}{cc}\text { Prenatal } & 21(58.3)[M(S D)=24.67(5.22) \text { weeks }] \\ \text { Postnatal } & 15(41.7)\end{array}$

Type of congenital anomaly

Congenital heart disease

$14(38.9)$

Nervous system anomalies

$4(11.2)$

Digestive system anomalies

$3(8.3)$

Urinary system anomalies

$9(25.0)$

Oro-facial clefs

$3(8.3)$

Limb anomalies

$3(8.3)$

Hospitalization

Yes

$16(44.4)$

No

$20(55.6)$

Need for surgery

Yes

$11(30.6)$

No

$25(69.4)$

${ }^{\dagger} p<.10 .{ }^{* *} p<.01$. 
Table 2 - Pearson correlations between socio-demographical and clinical variables, satisfaction with support and parental adjustment

\begin{tabular}{|c|c|c|c|c|c|c|c|c|c|}
\hline & $M(S D)$ & 5 & 6 & 7 & 8 & 9 & 10 & 11 & 12 \\
\hline 1.Age & & $-.34^{*}$ & .02 & -.02 & .18 & -.18 & -.00 & .12 & .16 \\
\hline 2.Educational level & & -.15 & -.05 & $-.34^{*}$ & .06 & -.11 & -.26 & .09 & -.26 \\
\hline 3.Parity & & -.12 & -.22 & $-.33^{*}$ & -.32 & $-.33^{\dagger}$ & $-.35^{*}$ & -.21 & -.08 \\
\hline 4.Timing of diagnosis & & -.23 & -.10 & $-.36^{*}$ & -.15 & $-.28^{\dagger}$ & $-.33^{\dagger}$ & -.13 & -.04 \\
\hline 5.Support Family $-\mathrm{M}$ & $84.31(16.36)$ & 1 & .28 & $.72^{* *}$ & .24 & .05 & .15 & $-.54^{* *}$ & $-.47^{* *}$ \\
\hline 6.Support Family -F & $87.49(13.67)$ & & 1 & $.43^{* *}$ & $.68^{* * * *}$ & -.17 & -.22 & -.26 & $-.33^{\dagger}$ \\
\hline 7.Support Friends -M & $67.08(30.62)$ & & & 1 & $.37^{*}$ & .02 & .11 & $-.37^{*}$ & $-.41^{*}$ \\
\hline 8.Support Friends $-\mathrm{F}$ & $71.97(24.51)$ & & & & 1 & -.27 & $-.38^{*}$ & $-.33^{*}$ & $-.53^{* *}$ \\
\hline 9.Burden - M & $25.57(8.24)$ & & & & & 1 & $.70^{* * *}$ & $.47^{* *}$ & $.31^{\dagger}$ \\
\hline 10.Burden $-\mathrm{F}$ & $25.65(8.26)$ & & & & & & 1 & $.45^{* *}$ & $.47^{* *}$ \\
\hline 11. Parenting stress $-\mathrm{M}$ & $65.03(20.06)$ & & & & & & & 1 & $.58^{* * * *}$ \\
\hline 12. Parenting stress $-\mathrm{F}$ & $63.28(15.13)$ & & & & & & & & 1 \\
\hline
\end{tabular}


Table 3. Effects of satisfaction with support from family and friends on maternal and paternal adjustment: Actor and partner effects

\begin{tabular}{|c|c|c|c|c|}
\hline & \multicolumn{4}{|c|}{ Maternal adjustment } \\
\hline & \multicolumn{2}{|c|}{ Burden } & \multicolumn{2}{|c|}{ Parenting stress } \\
\hline & $\beta$ & $t$ & $\beta$ & $t$ \\
\hline \multicolumn{5}{|l|}{ Step 1 [control] } \\
\hline Parity & -.42 & $-2.24^{*}$ & & \\
\hline Timing of diagnosis & -.17 & -0.94 & & \\
\hline \multicolumn{5}{|l|}{ Step 2 [actor and partner effects] } \\
\hline Support family_mother & .17 & 0.74 & -.60 & $-2.87^{* *}$ \\
\hline Support friends_mother & -.16 & -0.64 & .16 & 0.72 \\
\hline Support family_father & -05 & 0.21 & .02 & 0.09 \\
\hline \multirow[t]{5}{*}{ Support friends_father } & -.44 & $-2.01^{\dagger}$ & -.26 & -1.32 \\
\hline & \multicolumn{2}{|c|}{$\begin{array}{c}F_{6,29}=2.08 \\
\text { Adjusted } R^{2}=.16\end{array}$} & \multicolumn{2}{|c|}{$\begin{array}{c}F_{4,31}=4.21^{* *} \\
\text { Adjusted } R^{2}=.27\end{array}$} \\
\hline & \multicolumn{4}{|c|}{ Paternal adjustment } \\
\hline & \multicolumn{2}{|c|}{ Burden } & \multicolumn{2}{|c|}{ Parenting stress } \\
\hline & $\beta$ & $t$ & $\beta$ & $t$ \\
\hline \multicolumn{5}{|l|}{ Step 1 [control] } \\
\hline Parity & -.45 & $-2.74^{*}$ & & \\
\hline Timing of diagnosis & -.18 & -1.12 & & \\
\hline \multicolumn{5}{|l|}{ Step 2 [actor and partner effects] } \\
\hline Support family_father & .04 & 0.21 & .15 & 0.78 \\
\hline Support friends_father & -.61 & $-3.18^{*}$ & -.54 & $-2.88^{* *}$ \\
\hline Support family_mother & .23 & 1.15 & -.39 & $-1.97^{\dagger}$ \\
\hline \multirow[t]{2}{*}{ Support friends_mother } & -.06 & -0.27 & .01 & 0.02 \\
\hline & \multicolumn{2}{|c|}{$\begin{array}{c}F_{6,29}=4.19^{* * * *} \\
\text { Adjusted } R^{2}=.35\end{array}$} & \multicolumn{2}{|c|}{$\begin{array}{c}F_{4,31}=5.64^{* *} \\
\text { Adjusted } R^{2}=.35\end{array}$} \\
\hline
\end{tabular}

${ }^{\dagger} p<.10 .^{*} p<.05 .{ }^{* * *} p<.01 .^{* * * *} p<.001$. 
Table 4. Partner effects of satisfaction with support on adjustment: Examining indirect effects

\begin{tabular}{|c|c|c|c|c|c|c|c|}
\hline $\begin{array}{c}\text { Partner's perception } \\
\text { of support (X) }\end{array}$ & $\begin{array}{c}\text { Partner's } \\
\text { adjustment }\end{array}$ & $\begin{array}{c}\text { Actor's } \\
\text { adjustment }\end{array}$ & $\begin{array}{c}\text { Effect of } \mathrm{X} \\
\text { on } \mathrm{M}\end{array}$ & $\begin{array}{l}\text { Effect of } \\
\text { M on } \mathrm{Y}\end{array}$ & $\begin{array}{l}\text { Direct } \\
\text { effect }^{\mathrm{a}}\end{array}$ & Indirect effect $^{\mathrm{b}}$ & $\begin{array}{l}\text { Total effect } \\
\text { of X on Y }\end{array}$ \\
\hline & (M) & $(\mathrm{Y})$ & $B(S E)$ & $B(S E)$ & $B(S E)$ & $\begin{array}{c}B(S E) \\
{[95 \% \mathrm{CI}]}\end{array}$ & $B(S E)$ \\
\hline $\begin{array}{l}\text { Paternal satisfaction } \\
\text { with support from } \\
\text { friends }\end{array}$ & Paternal burden & Maternal burden ${ }^{c}$ & $-.55(.14)^{* * * *}$ & $.61(.17)^{* * * *}$ & $-.08(.16)$ & $-.34(.13)[-.66,-.13]$ & $-.42(.15)^{*}$ \\
\hline $\begin{array}{l}\text { Maternal satisfaction } \\
\text { with support from } \\
\text { the family }\end{array}$ & $\begin{array}{c}\text { Maternal parenting } \\
\text { stress }\end{array}$ & $\begin{array}{c}\text { Paternal parenting } \\
\text { stress }^{\mathrm{d}}\end{array}$ & $-.54(.14)^{* * * *}$ & $.45(.16)^{*}$ & $-.23(.16)$ & - .25 (.13) [-..64, -.05] & $-.47(.15)^{* *}$ \\
\hline
\end{tabular}

Note. Standardized coefficients are presented. Significant indirect effects in bold.

${ }^{\mathrm{a}}$ Direct effect: effect of X on Y, controlling for M. ${ }^{\mathrm{b}}$ Indirect effect: effect of X on Y, through M. ${ }^{\mathrm{c}} F_{4,31}=7.74, p<.001$, Adjusted $R^{2}=.44 .{ }^{\mathrm{d}} F_{2,33}$ $=9.61, p<.001$, Adjusted $R^{2}=.33$.

${ }^{\dagger} p<.10,{ }^{*} p<.05,{ }^{* *} p<.01,{ }^{* * *} p<.001$. 